\title{
A SUSTAINABLE APPROACH TOWARDS HOUSING IN INDIA - PASSIVE DESIGN STRATEGIES AS A METHOD OF DESIGN
}

\author{
Anup Naik \\ BMS College of Architecture, \\ Bangalore, Karnataka, India
}

\begin{abstract}
Housing in India today experiences an excluded, commercialized approach, making every project money making opportunity for developers around. In a country where construction is majorly dominated by private developers and builders, community-driven spaces like a social habitat, exclude the very society occupying it.

An increasing crunch of space due to finite land availability for construction, loss of greener areas to everincreasing concrete jungles and, depleting resources demand a vertical, sustainable and affordable solution for present-day housing issues faced in the country.

Construction is the highest consumer of energy and the pressure on urban resources, with a requirement of almost 25 million housing units by 2030 (ETReality, 2019), calls for an energy-efficient or energy-saving solution.

This paper discusses theories, practices and a passive right approach, well-demonstrated using a case example. This paper streamlines on the importance of an allinclusive habitat which is socially active, economically affordable and, a sensitized sustainable answer to the modern-day, chaotic housing.
\end{abstract}

Keywords - Modern Housing, Sustainable, Passive-right, Inclusive, Urban crunch, Migration

\section{INTRODUCTION}

The idea of a sustainable edifice encompasses economy, surrounding environment, people and their social structure, efficiency and, legibility. The concept of modern housing demonstrated in this article is a layering of the abovementioned parameters in varying degrees in order to achieve a morphologically balanced campus. The belief is that each segment would lead to a multiplier effect, finally impacting the city as a whole, thus proposing an incremental building block for a sustainable future.

The attempt is to create sustainable habitat's that are holistic in performance by responding to, and balancing issues of environment, social lifestyles and economics. The built environment is a manifestation of the technological innovation. The way technologies are applied in design and construction of buildings, have direct implications on the amount of energy consumed. In the modern context, habitats represent environments that are artificially controlled and managed, reinforcing a problematic relationship between design and technology. In this light it will be interesting to investigate the link between -

- Economic Growth and Value creation

- Clean Environment and Green Development

- Caring Community and Public Participation

- Efficient Mobility and Safety/ Security

- Housing Quality and Low Carbon Lifestyle

The project discussed in this paper has set a target to become an example of "affordable yet sustainable residential neighbourhood development" in India and become international reference in due course. ITC Ltd (Imperial Tobacco Company of India Limited), a leading FMCG (FastMoving Consumer Goods) company in India, is redeveloping one of its existing single storey residential development spread over 150 acres to a multi-storeyed highdensity township of 43 acres named as "ITC Bhadrachalam Township" in the state of Andhra Pradesh, India.

\section{Aim of the paper}

Sustainability is an overarching concept, which ties adaptation and resilience together. The project attempts to create a sustainable habitat that is holistic in performance by responding to and balancing issues of environment, social lifestyles and economics.

\section{Objectives}

Reinforcing and exploring a design direction in order to costeffectively redevelop a traditional, horizontally spread, existing semi-urban township into a vertical yet sustainable and connected neighbourhood. The project brings together technology and innovative thinking to make housing affordable to all ensuring 'reuse, recycle, renew' principles. These objectives are achieved by focusing on following aspects of design:

1. Availability of Land: The project demonstrates an 
effort to move towards densification from ground to the vertical plane to ensure protection of agricultural lands by limiting sprawl of building footprint. A conscious effort is being made to reduce the impact of infrastructure development in terms of roads, drains, service trenches etc. by means of alternate techniques.

2. Water Conservation: Conventional strategy assumes piped water from the river as the only source. The strategy employed for the development is to integrate the potential of rainwater incident on site in a manner that increases water security as well as flood and drought resilience of the development.

3. Inclusive Circulation: Pedestrian network ensures an easy accessibility for residents to reach out to each other with reduced dependency on vehicular transportation or mechanical means of transportation.

4. Social Connect: This proposed industrial township in a rural area to provide accommodation along with all amenities and facilities near the workplace is a perfect example to create an economically, socially and environmentally sustainable community. This will reduce migration to urban spaces by providing comfortable and enriching live-work-play environment to talented workforce.

5. Sensitised Accessibility: This project is envisaged to provide a barrier free environment to ensure inclusive social environment by providing comfortable and harmonious living conditions to elderly and differently-abled people.

6. Significance: The project has set the target to become an example of affordability and sustainability across India and globally, thus setting a new language of development.

7. Public Participation: The project boasts of a one of its kind dedicated user workshop involving participation from end users ( 120 people) covering managers, employee union, ladies and younger population in different sessions. Such interaction brought the designers to understand the requirements of users, awareness about environmental consciousness among end users. The project follows an integrated design approach right from the beginning of the project and has involved active participation from different parties including end users, master planners, architects, landscape architects, environmentalist, geologist, engineers, cost consultants and water consultants.

\section{Scope and limitations}

This paper sets an example of sustainability in Andhra Pradesh, India and focuses on the three major aspects demonstrated in the case example. Despite sustainability as an outcome being universal, the methods and strategies considered to achieve it are completely subjective. Sustainability for the project considered revolves around affordability, optimum use of energy and social structure of people using it.

\section{CASE EXAMPLE}

\section{Introduction to Site - Bhadrachalam, Andhra Pradesh} The proposed site is located in Sarapakka Village, Khammam Dist., Andhra Pradesh. It is $4 \mathrm{kms}$ from the town of Bhadrachalam. National Highway-221 buffers the proposed site from the ITC Paper Mill factory. The complete Mill Unit at Bhadrachalam is spread over 500 acres of land comprising of production facilities, administration block, residential colony complete with facilities and required infrastructure. The proposed development shares boundaries with a school and an auditorium (Kala Bharti).

The scope of the Project is to accommodate people employed at the existing operations along with growth projections. The development plan envisions various unit types and modules for different workforce sections as well as necessary amenities, play areas, infrastructure and open spaces. The project shall demonstrate a high-standard, sustainable quality of life amongst various sections of users. The proposed campus is expected to be a sustainable, contemporary and integrated housing community, built at optimum cost. This will also be designed to minimize impact of hot climate and enhance quality of life comparable to other operating locations of ITC.

Nearest Railway Station: Kottagudam (30kms),

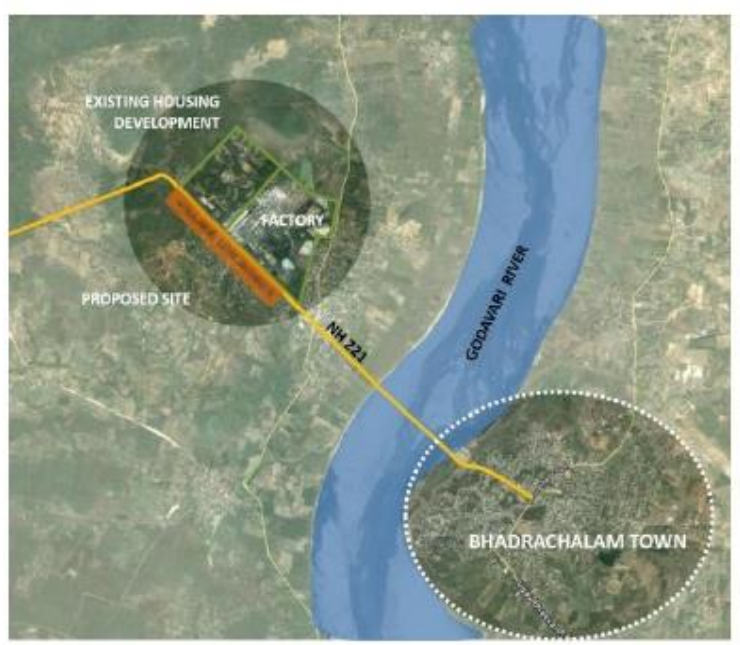

Nearest Airport: Hyderabad (8hrs drive); Vijayawada (4hrs drive) 


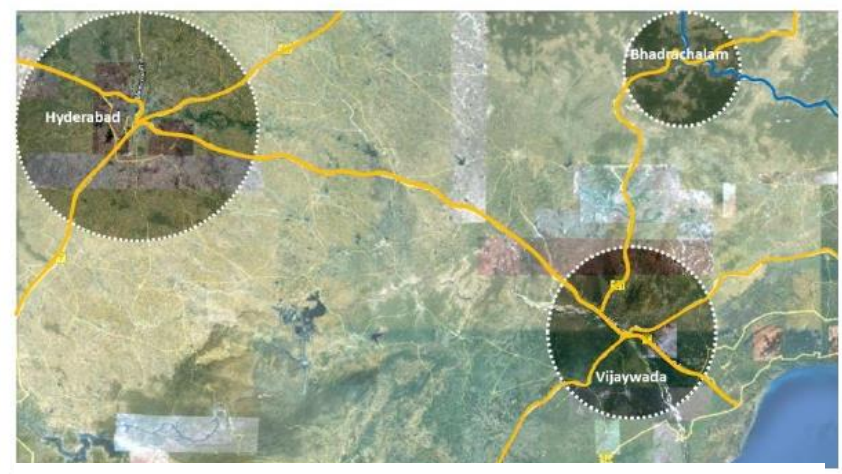

Figure 2a \& b: Maps of Bhadrachalam Source: Google Maps.

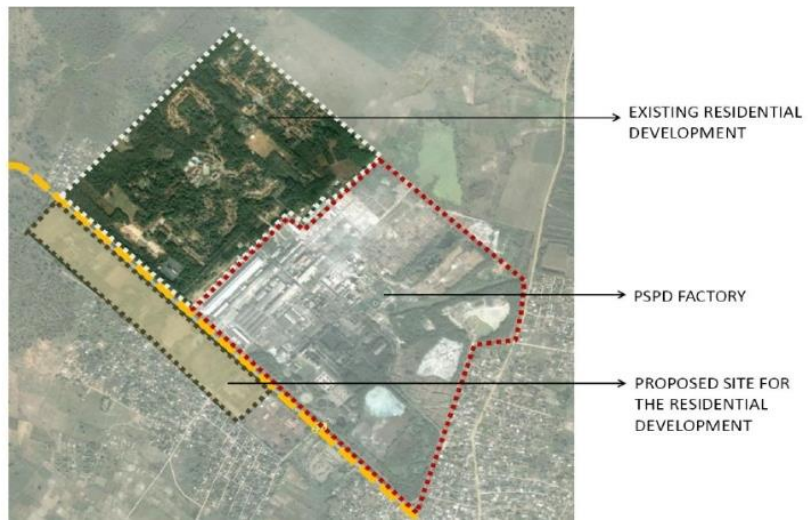

Figure 1: Map showing surrounding context of the site. Source: Google Maps

\section{Climate Analysis}

Bhadrachalam, a municipality in Khammam district, is located in the Indian state of Andhra Pradesh with latitude \& longitude of $17.66 \mathrm{~N} \& 80.88 \mathrm{E}$ respectively. It has an average elevation of 63 meters (164 feet) and with time zone of GMT+5.5. As per the climate zone map of India, provided in National Building Code 2005 and the Energy Conservation Code 2007, Bhadrachalam is categorized as Warm \& Humid Climate.

The wind, sun and comfort analysis carried out at site level. The analysis shows that though wind will not cause any hazard on site, temperature in the microclimate may rise as high as 47deg C. In order to avoid heat island effect and rise in microclimate temperatures, mitigation measures need to be incorporated in the landscape design. Also, the wind analysis shows that due to high density, all blocks/dwellings units in the leeward side, shall require fenestrations to be introduced in order to enhance natural ventilation in the months when outside microclimate is favourable.

The solar analysis shows that external shading is playing an important role to achieve lower indoor air temperature and

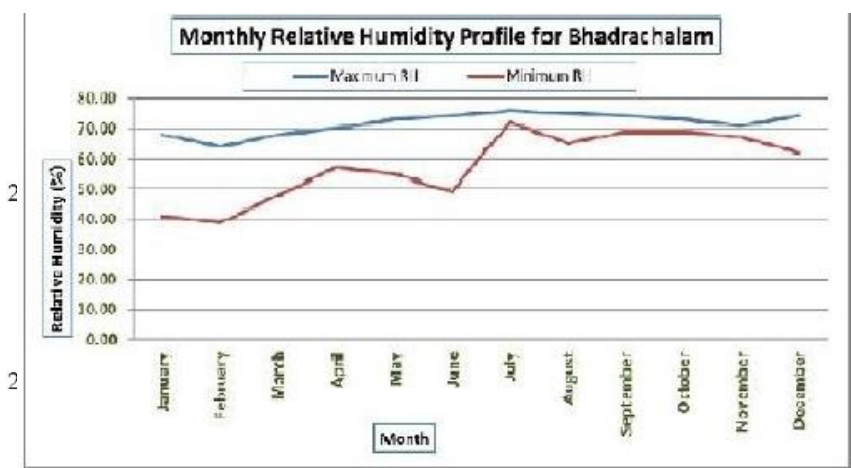

Annual hours of occurrences for range of hourly ambient temperature profile

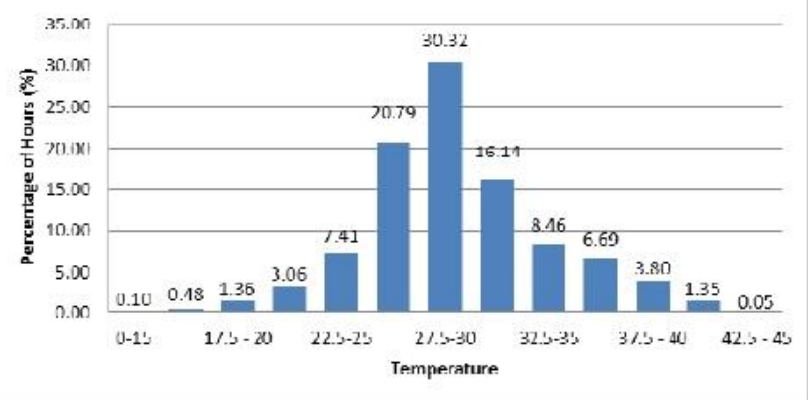

Figure 3: Graphs analysing the micro-climate of the region Source: Climatic Study and Analysis provided by TERI Bangalore Preliminary Energy \& Water Report Project Code: $2011 B G 04$

MRT (Mean Radiant Temperature). Also, the analysis shows that un-insulated walls perform better all across the day in warm-humid climate zone in the proposed arrangement of the blocks.

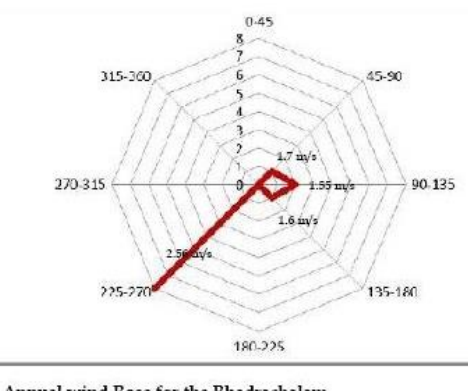

Figure 4: Sun Angle analysis and Wind rose diagram for the proposed project considered. Source: Climatic Study and Analysis provided by TERI - Bangalore Preliminary Energy \&

Annual wind Rose for the Bhadrachalam Water Report Project Code: $2011 B G 04$

Preliminary water analysis carried out to quantify water demand reduction possible at building level. This in comparison to GRIHA benchmark shows $66 \%$ reduction possible in building water demand. Rain water harvesting potential has also been analysed. 


\section{Objectives of Design}

- Sustainable, comprehensive habitat

- Honorable \& sensitive to the neighborhood

- Affordable, cost-effective construction

- Responsive to climate \& context

- Placeholder development wrt creativity, benchmarking

- $\quad$ Reuse - Recycle - Renew by reinforcing a design direction to cost-effectively redevelop a traditional, horizontally spread, existing semi-urban township into a vertical yet sustainable and connected neighbourhood. The project brings together technology and innovative thinking to make housing affordable to all.

- Passive Design is an integrated assessment of climate and natural resources of a region which translates into design elements, techniques and strategies for the built environment. The intent to reduce a building's energy consumption by minimizing or eliminating mechanical systems, which are conventionally used to regulate thermal \& visual comfort parameters for the users.

- Ecosystem Project aspires to encourage biodiversity by enhancing environmental and ecological potential, vegetation strategy and use of indigenous landscape. Project extends the character of the forest into the development, thereby contextualizing the site through natural tendencies and environmental conditions.

- Water Security by evaluating the water potential of the site including assessment of total incident rainfall, as well as addressing built and non-built areas for managing and harvesting rain / storm water. Ultimately, achieve zero discharge from the site where no incident water is allowed to leave the development site.

- Community Linkage by extending the community interaction space beyond the ground plane to higher levels of building. These social interaction spaces at higher levels act as markers to define the identity of individuals and cluster of dwelling units.

- Security achieved by developing safe edges to the development and addressing effectively the points of conflict between vehicular and pedestrian movement. Along with traffic control, creating internal circulation/ network connections, screens and buffers provide safety as well as control issues like glare and pollution.

\section{Public Participation}
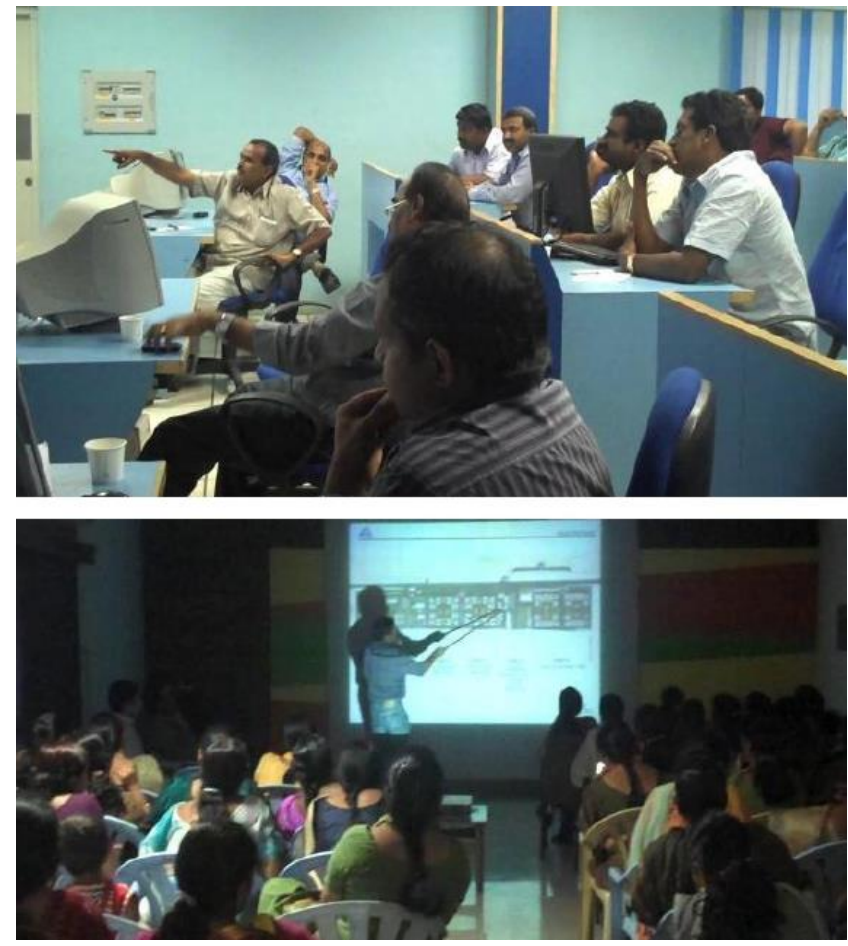

Figure 5: Public Participation including stakeholders and investors to end users and consultants.

Source: Author

Involving stakeholders in projects and decision-making processes has its advantages and disadvantages. Thereby in this project, transparency was achieved, stakeholders were well-informed and provided valuable inputs to improve outcomes and build consensus.

The project boasts of a one of its kind dedicated user workshop involving participation from Stakeholders, including - end users (120 people) covering managers, employee union, ladies and younger population in different sessions. Such interaction brought the designers to understand the requirements of users and awareness about environmental consciousness among end users.

The project follows an integrated design approach right from the beginning of the project and has involved active participation, design workshops from different parties involved in growth and development of this project.

\section{Design Drivers}

There are four predominant aspects defining the design of the Integrated Residential scheme: 

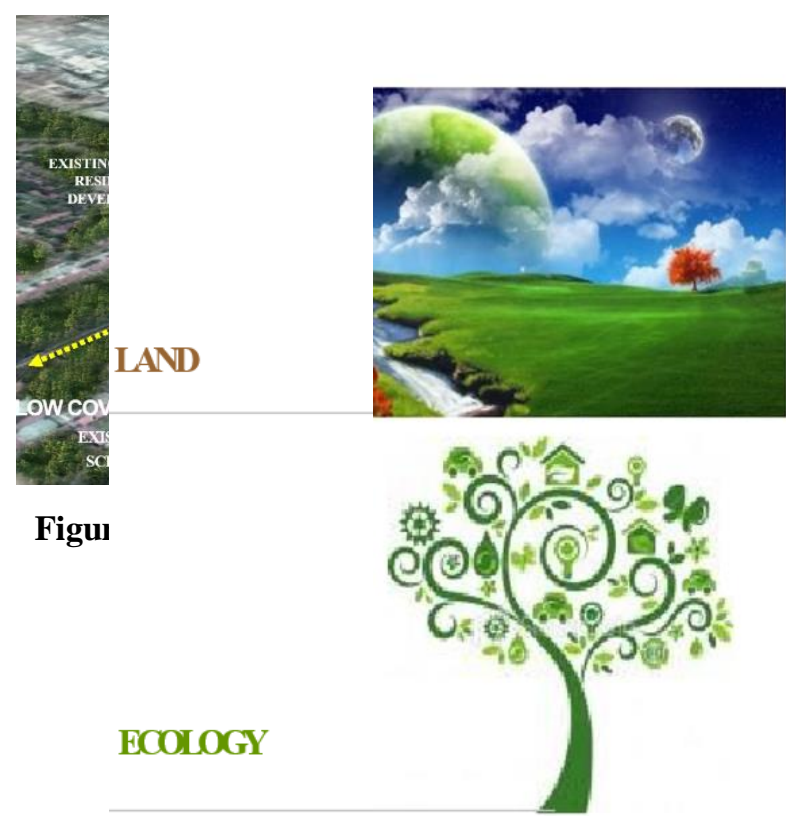

PEOHE

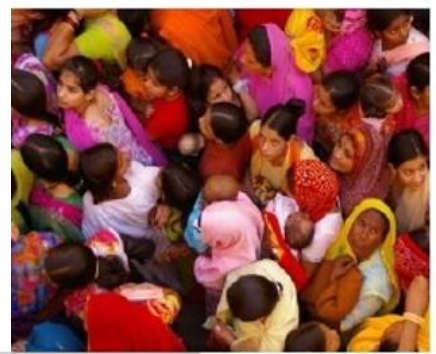

\section{AFFORDABIIIIY}

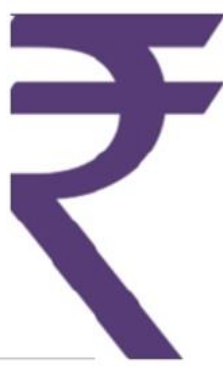

\section{Design Initiatives: LAND}

Project aims at protection of agriculture \& forest lands by limiting sprawl of the building footprint \& hence verticalisation of the development. Existing development encompasses 900 families in 110 acres, whilst the proposed development houses 1500 families in 43 acres. The project demonstrates an effort to move towards densification from ground to the vertical plane to ensure protection of agricultural lands by limiting sprawl of building footprint.

With ground coverage of $18 \%$, project minimises land disturbance and maximises green and open spaces. Increased density leads to increased productivity. Higher density neighbourhood are provided with a variety of circulation and amenities options and are connected with diversity, social unity and cultural growth. A conscious effort is being made to reduce the impact of infrastructure development in terms of roads, drains, service trenches etc. by means of alternate techniques.

\section{Low Coverage High Density}
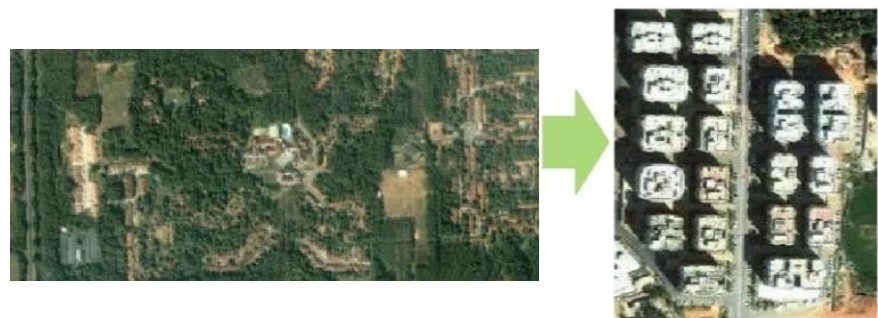

Figure 8: High Density $-1 / 20^{\text {th }}$ acre per dwelling unit Source: Google maps

Figure 8: Low Density $1 / 6^{\text {th }}$ acre per dwelling unit

Source: Google Maps

The proposed development is strategically classified into 2 parts: Managers Section, Employee Section. Further, the

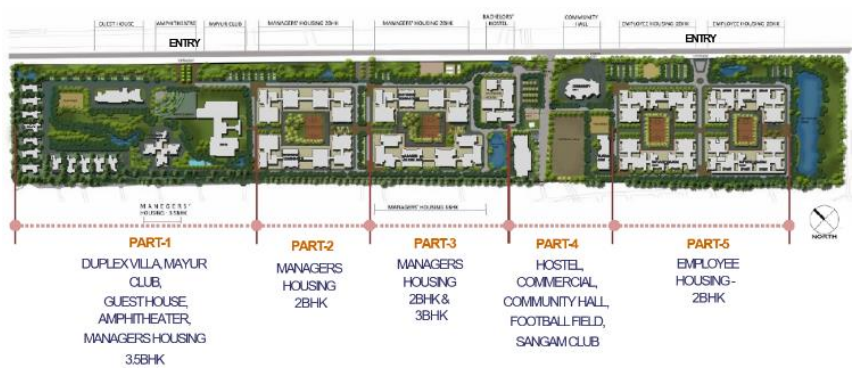

Figure 9: Distribution and segregation of various housing units and amenities considered Source: Author

Managers Parcel is zoned as - Villas, High-Rises, Club House, Guest House and Hostel. The Employee parcel comprises of High-rises and Club House. Common facilities such as Commercial spaces, Community Hall, Sports Field, Amphitheatre are distributed across the site. 


\section{International Journal of Engineering Applied Sciences and Technology, 2020 \\ Vol. 5, Issue 1, ISSN No. 2455-2143, Pages 239-251 \\ Published Online May 2020 in IJEAST (http://www.ijeast.com)}

\section{Topography of the Site}

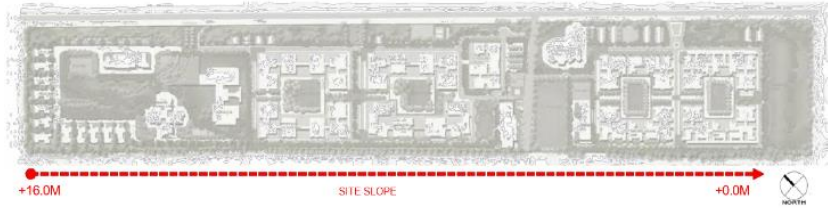

Figure 10: Natural topographical gradient of the site Source: Author

Project observes methods to preserve and protect the natural geo-morphological features of the site by working with the existing topography and avoiding excessive modulations to the terrain. Project Site experiences a slope of $\sim 16 \mathrm{~m}$ across the length of the site. The benefit of the slope has been carried out throughout the project - from street network to parking levels, from buildings to landscape. The street networks as well as the landscape follow the
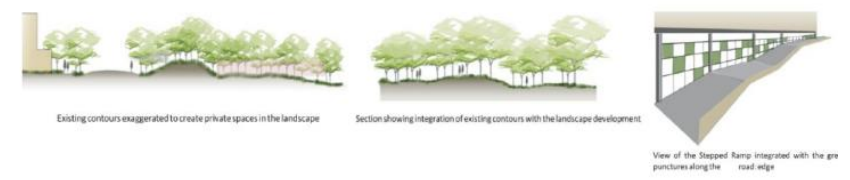

Figure 11: Natural integration of built with the topographical terrain Source: Author

terrain creating a dramatic visual experience.

\section{Integration of Landscape Elements}

Landscape elements are designed so as to emphasise the natural terrain and accommodate the requirements of the projects thus utilising the landscape elements in order to achieve the set objectives and goals of sustainability.

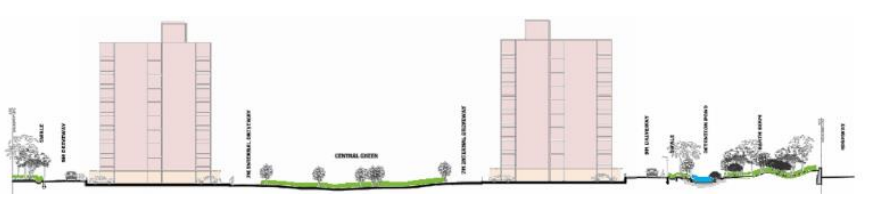

Figure 12: Section1- Through block and central green space Source: Author

\section{Preserving Natural Terrain}

For Example, parking requirement of buildings are achieved by providing stilt parking. By eliminating the system of basement parking, project demonstrates maintenance of natural terrain. In turn, each of the stilt parking in the blocks are modulated according to the surrounding levels as well as stepped internally creating internal islands of parking.

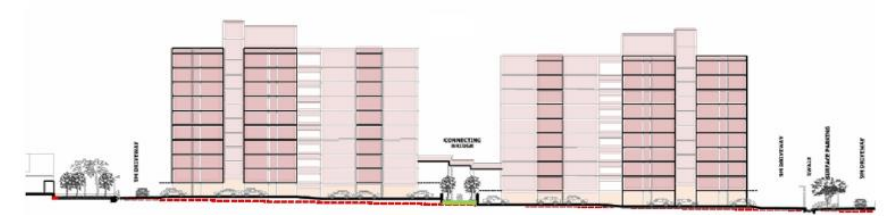

Figure 14: Section 2- Longitudinal section across block Source: Author

\section{Green Connect}

Further articulating the desired lines and paths, blocks provide breaks in mass, creating porous walkways connecting various spaces and activities of the development. Individual blocks capture the advantage of the terrain by providing pedestrian connect to streets and open spaces. The green texture maintains the flow of landscape, while materials reinforce the separation of space, together accentuating the entry to the blocks and
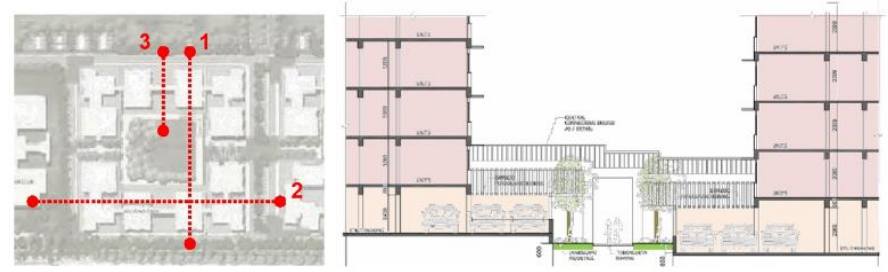

Figure 15 : Key Plan and Section 3: Detail of green connect between parking levels Source: Author

visuals of the central green.

\section{Noise and Pollution Control}

One of the major concerns of the development is its adjacency to the highway. Methods are employed to mitigate the problem, by creating complementary strategies and a variety of buffer treatments to control both noise and visual intrusions by buffering the edges using natural terrain.

Various buffer treatments are designed to address specific issues, using combination of strategies to provide functional as well as aesthetic solutions. Commonly used are Earth Berms or Mounds.

\section{Structural berm treatments:}

Gabion Walls, Infill Walls, Barriers, Fences etc.

\section{Spatial berm treatments:}

Levels, Distance, Scale etc.

Vegetative berm treatments:

Trees, Shrubs, Green Walls,

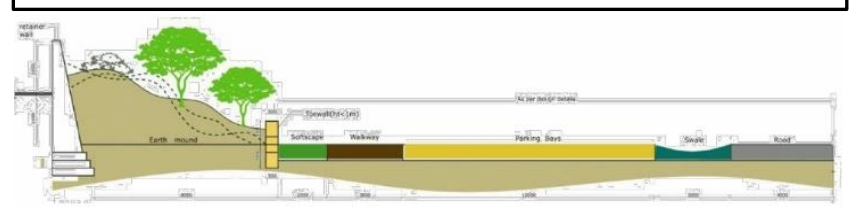

Figure 13: Section showing mounds used to obstruct distraction from adjacent highway

7. Earth Balance 


\section{International Journal of Engineering Applied Sciences and Technology, 2020 \\ Vol. 5, Issue 1, ISSN No. 2455-2143, Pages 239-251 \\ Published Online May 2020 in IJEAST (http://www.ijeast.com)}

Project aims at achieving an earthwork balance on two fronts, firstly by minimizing cut (excavation) and fill (embankment) volumes. Secondly, by utilizing the earth available on site. This has been developed by reusing the excavated earth for foundations \& underground services, to create the mound along the highway edge. As well as, top soil conservation by careful ret-use into landscape areas.

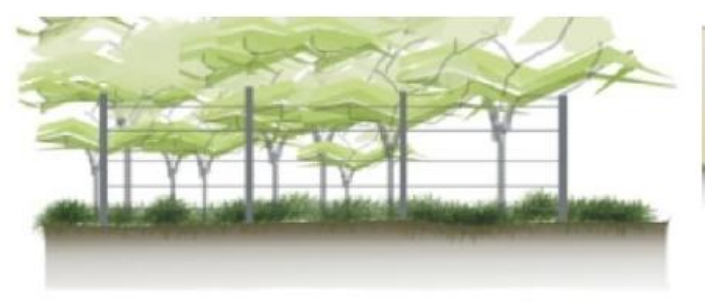

Typical elevation of flat settlement edge with fencing and vegetation.

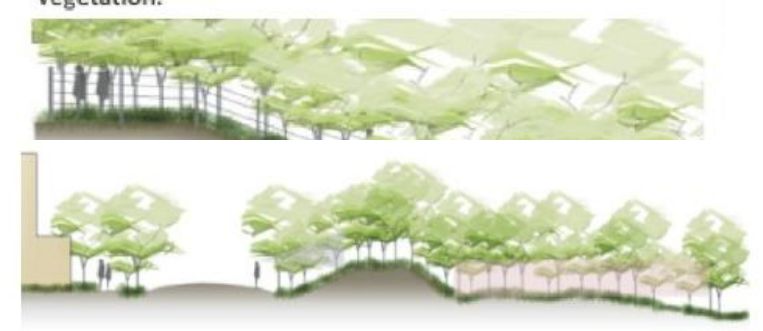

Existing contours exaggerated to create private spaces in the landscape

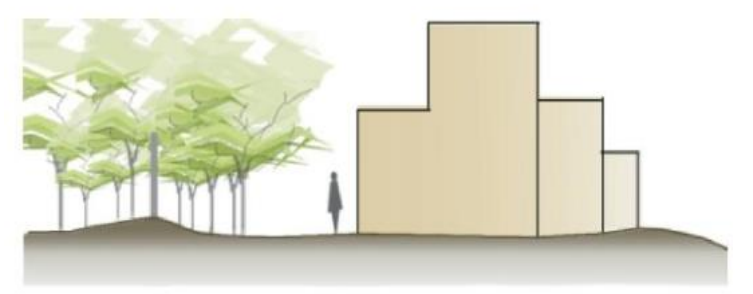

Typical section showing boundary wall raised to visually reduce the scale of the highrise development.

Figure 16: Use of excavated earth on site. Source: Author

\section{Initiatives: WATER}

Conventional strategies of using piped water from the river is avoided. The system employed for this project is to integrate the potential of rainwater incident on site in a manner that increases water security as well as flood and drought resilience of the development. In a broader scale, the project determines measures and controls for site drainage that does not disturb the regional drainage pattern, impacting the surrounding village settlements.

Project has envisioned a water cycle to meet the development's needs by reducing fresh water demand and by integrating rain water harvesting, storm water management, recycling and reuse of waste water. Project exemplifies the importance of water by developing measures and design responses that are passive in nature and optimize resource's conservation and utilization. Preserving open space is critical to maintaining water quality at the regional level.

\section{Water as a Resource}

\section{Vegetated Swales}

Direct and collect storm water.

\section{Percolation Pits}

Harvest incident rain \& reinforce passive drainage.

\section{Permeable Surfaces}

Maximized to allow infiltration and recharge.

\section{Grading of Land}

Manage water and control erosion.

Traditional Storm Water Management is based on the premise that the incident rainwater should be routed and expelled from the site in the shortest possible duration. Sustainable principles of water management, based on the concept of utilising the sites contours to maximise the potential.

The project demonstrates a divergence in conception by questioning and evaluating at the very inception rather than rendering the existing as more efficient. Large, continuous areas of open space reduce and slow the runoff, absorb sediments and help maintain healthy ecosystem. In order to ensure well-functioning watersheds, project provides large, undisturbed and open spaces to absorb, filter, and store rainwater. Rainwater incident on ground is managed in varying ways depending on the surface they flow across. The objective is to achieve zero discharge from the site, i.e., no water incident is allowed to leave the development site.

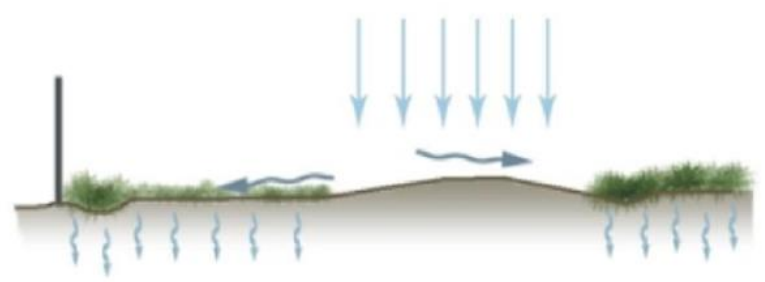

Figure 17: Water drainage strategy along the road with dispersion trenches along either edge

Source: Author

\section{Storm Water Management Plan}

Effective control of runoff in the development is demonstrated by reducing the flow of storm water, as well as reducing pollutant discharge. Minimal hardscape is maintained. Driveway paving are provided with strips of hard surface only at the car wheel base, leaving the rest of the area soft thus, minimising runoff. 


\section{Initiatives: CIRCULATION}

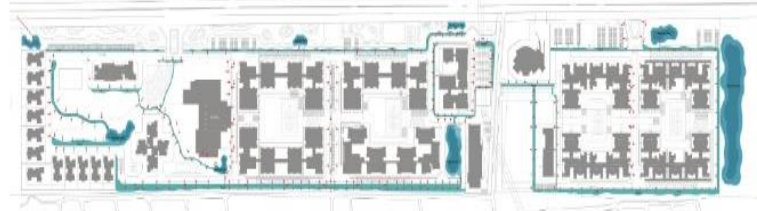

Figure 18: Storm water management plan Source: Author

\section{Pervious Surfaces}

Minimizing impact of paved spaces helps increase ground water recharge by maximizing pervious surfaces, alternate options to traditional street \& parking area paving systems.

Storm water runoff from paved surfaces is directed to swales or bio-retention areas, which are further collected in a shallow detention pond, allowing the runoff to in-filter into the ground. Swales are shallow with a parabolic cross section. They are used to move water gently from one part of the site to another. At their terminus, swale spread the channelized water making it a sheet drainage system. For slow flowing water channels, just a grass swale is enough but for speedier ones, non-vegetative materials, like boulders or stone aggregates are used.

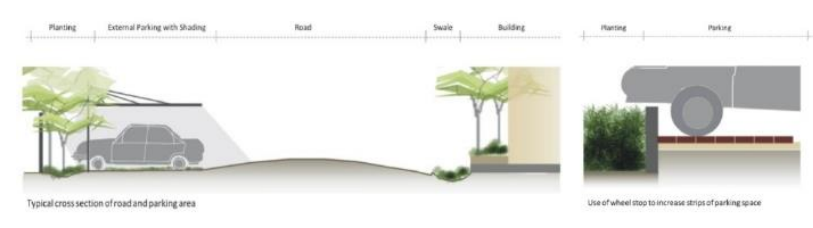

Figure 19: Surface treatment in parking areas Source: Author

\section{Swales}

Systems of swale / bio-retention areas employed to minimize built-up drain systems and allow infiltration.
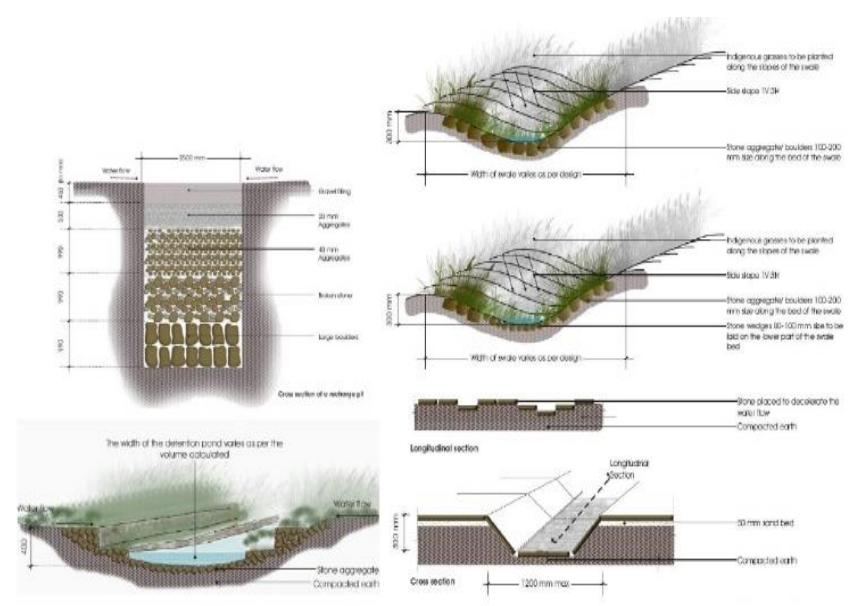

Figure 20: Various forms of swales used in the considered project Source: Author
The development demonstrates a hierarchy of street network and traffic zones. The internal vehicular traffic pattern forms a peripheral loop to the development as well as loop around the block clusters. The open spaces

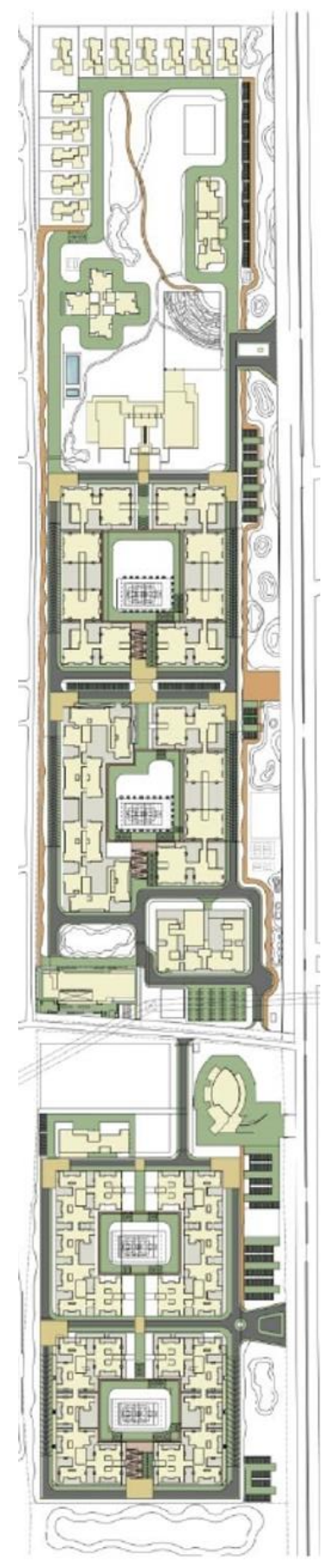

Figure 21: Site Circulation Plan Source: Author 


\section{International Journal of Engineering Applied Sciences and Technology, 2020 \\ Vol. 5, Issue 1, ISSN No. 2455-2143, Pages 239-251 \\ Published Online May 2020 in IJEAST (http://www.ijeast.com)}

between the blocks are pedestrian-only zones. The development also features a peripheral shaded jogging track that is well-vegetated and soft paved.

The internal driveways are classified as high traffic and low traffic roads - differentiated by the peak number of users it carries. High traffic roads are hard paved, which connect the entries and exits of high-rises, while low traffic roads are covered with soft materials, which connect the low-rises (such as villas) and internal emergency driveways and surface parking areas. The entry zones to each block are articulated through use of material and vegetation. The internal zones formed by 2 blocks are completely traffic free, allowing for easy pedestrian connect and safety in play areas. Each block cluster is linked to the adjacent clusters through internal pedestrian network that meander through the varying levels of the site.

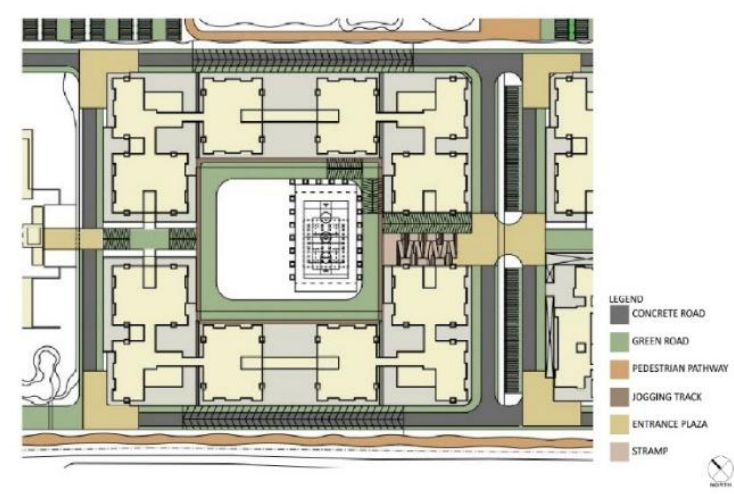

Figure 22: Block Circulation Plan

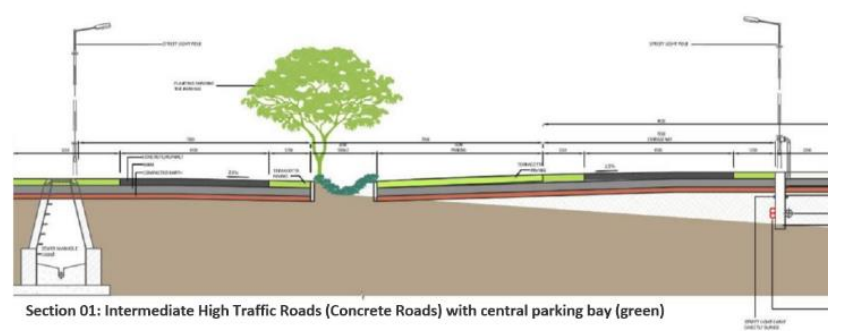

Figure 23: Section showing intermediate high-traffic roads (concrete roads) with central parking bay (green) Source: Author

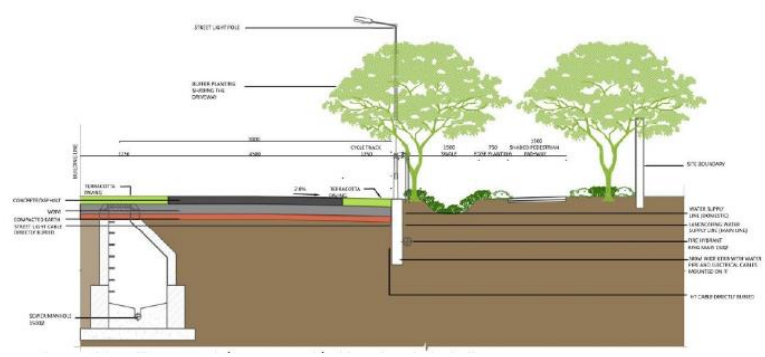

Figure 24: Section showing high-traffic loop roads (concrete roads) with swale and edge buffer Source: Author

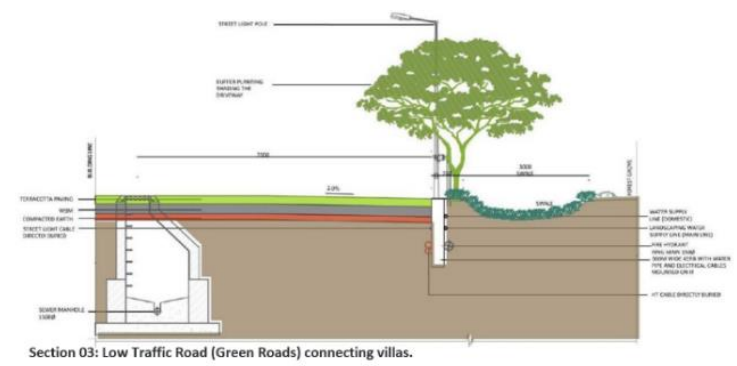

Figure 25: Section through low-traffic (green roads) connecting villas Source: Author

\section{Initiatives: COMMUNITY LINKAGE}

\section{Social Connect}

Relocation of residents from large spread community to a compact high-rise development has brought many challenges with itself. Measures have been taken to recreate similar social fabrics that bring a sense of identity. The existing colony houses are organized as 20 homes to a core. The same scale is replicated in the proposed development which creates 2 cores of 10 units each connected through corridors and bridges. The visual connect to the street frontage affected by the detachment due to high-rise is re-created by community linkages such as corridors and landscaped terraces, thereby enhancing the sense of belonging among users.

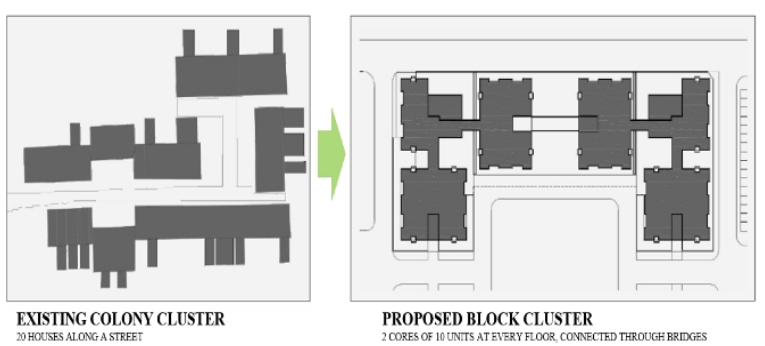

Figure 26: Before and after of the housing units of the considered project

Source: Author

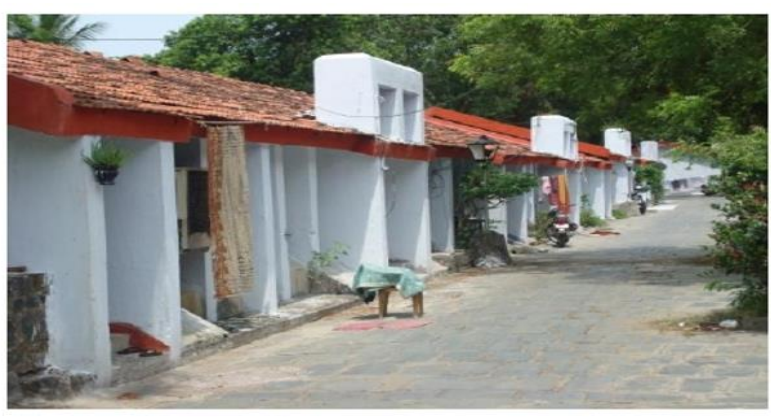

Figure 277: Character of surrounding streets 
Source: Author

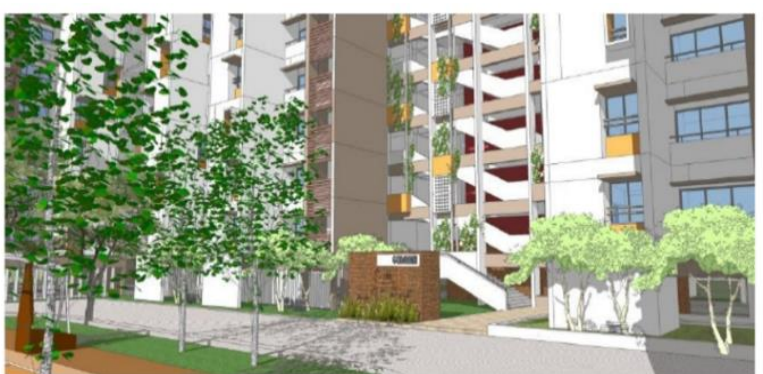

Figure 288: Proposed character of streets Source: Author

The development is sensitive to the surrounding social fabric. The public road connecting the adjacent villages to the highway is treated to function as a more porous and interactive space that allows for multiple users and activities to co-exist. The commercial block is strategically located along the public road, creating a transition between the public - private realm. The commercial space also allows for the sustenance of the surrounding villages through retail shops and dedicated hawker zone. The commercial block also overlooks the football field, providing recreational facilities.

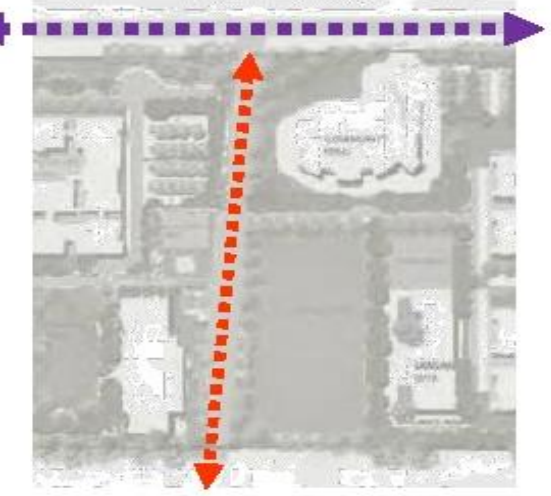

Figure 29: Existing connecting pathways of the site Source: Author

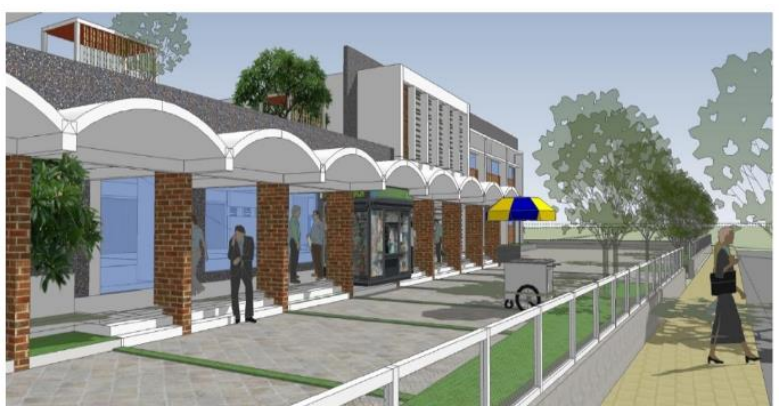

Figure 30: Commercial activities along the connecting pathways

Source: Author

\section{Defining Nodes}

Urban nodes such as site entry, building entry and exits, street-block interface, community plazas are articulated through use of material and vegetation.
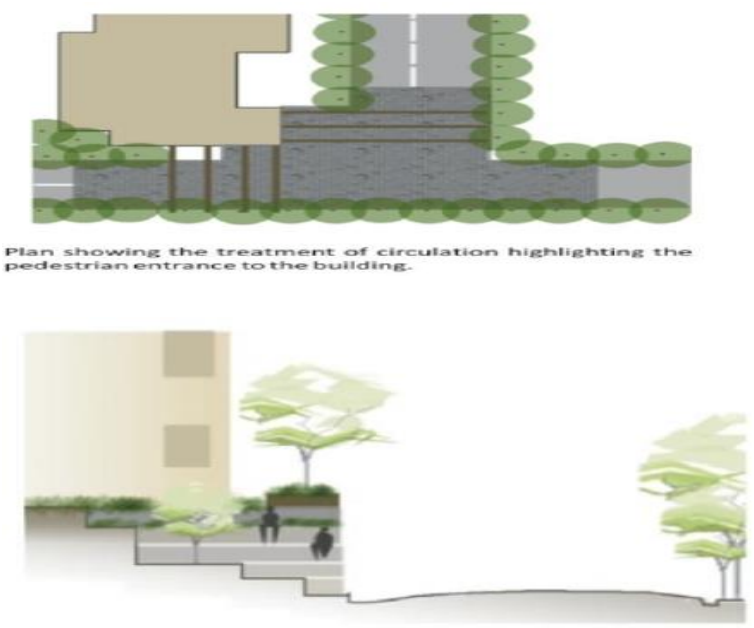

Integrated planting and swale along the ramp edge

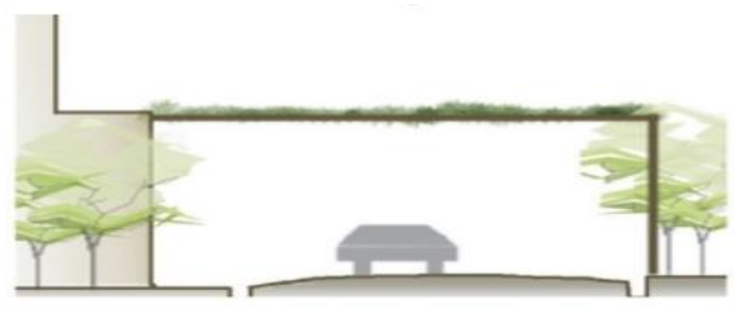

Section along the plaza in front of the lobby area

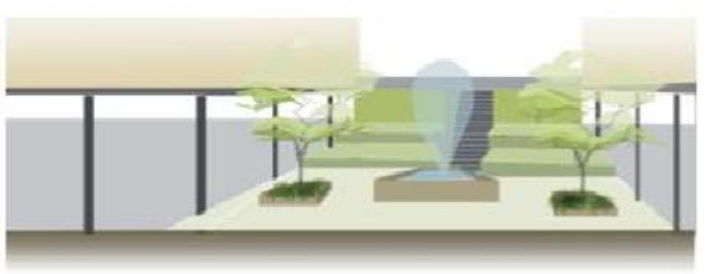

View of landscape court formed along the circulation

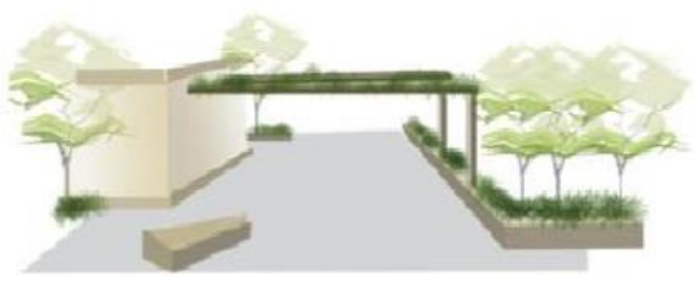

Vew of pergola space to define the entrance.

Figure 31: Nodes across the site Source: Author

\section{Thread and Beads}

Pedestrian network ensures an easy accessibility for residents to reach out to each other with reduced dependency on vertical transportation or mechanical 


\section{International Journal of Engineering Applied Sciences and Technology, 2020 \\ Vol. 5, Issue 1, ISSN No. 2455-2143, Pages 239-251 \\ Published Online May 2020 in IJEAST (http://www.ijeast.com)}

means of transportation. The corridors in the buildings are not limited to the purpose of connection, the role has been expanded to linking numerous units to centralised core as well as providing multiple access nodes to reduce dependency on restricted mechanical modes of vertical transport.

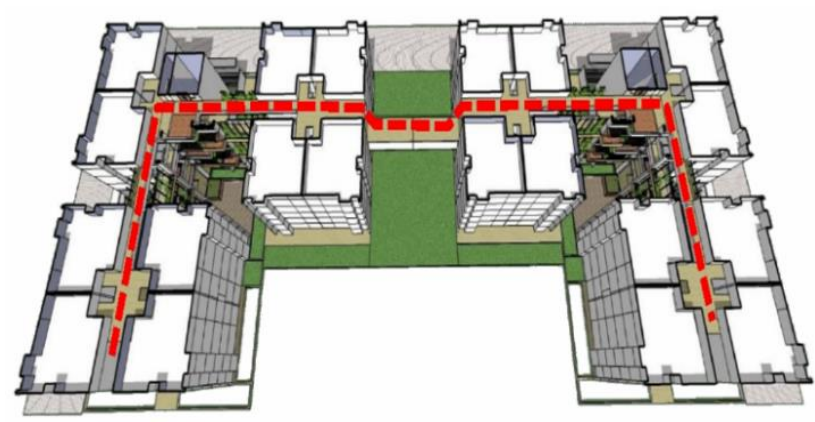

Figure 32: Top view of a block highlighting connecting corridors

Source: Author

Connecting bridges link sections of the block, extending the feel of community. The experience of the transitional levels is captured by dramatic alternating of corridors and break out spaces.

Corridors serve as thread of connection joining dwelling units as beads.

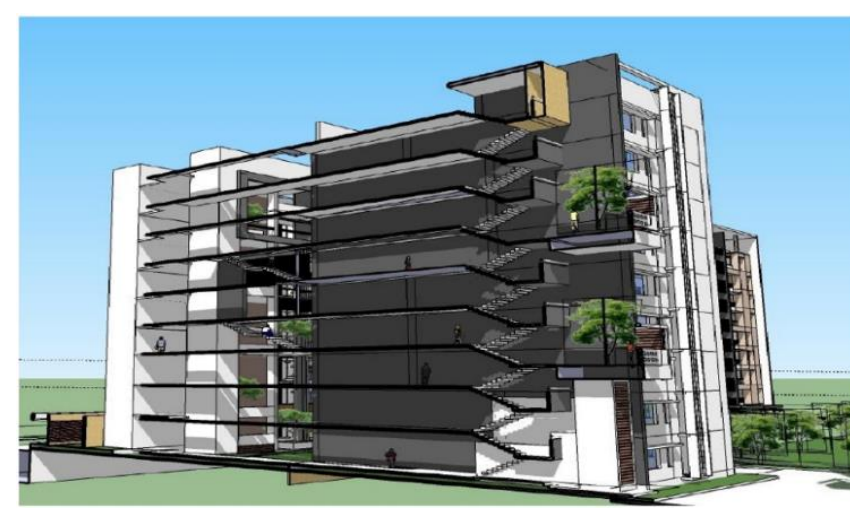

Figure 33: View showing internal common spaces of movement across the building block Source: Author

\section{Pedestrian Connect}

Pedestrian network ensures an easy accessibility for residents to reach out to each other without the fear of fastmoving vehicles. These pedestrian connections also form highly interactive zones for the residents, thus, reinstalling the sense of belonging and responsibility towards their social community and physical environment. These spaces promote interactions across different ages, gender and social background thus closely knitting the entire community.

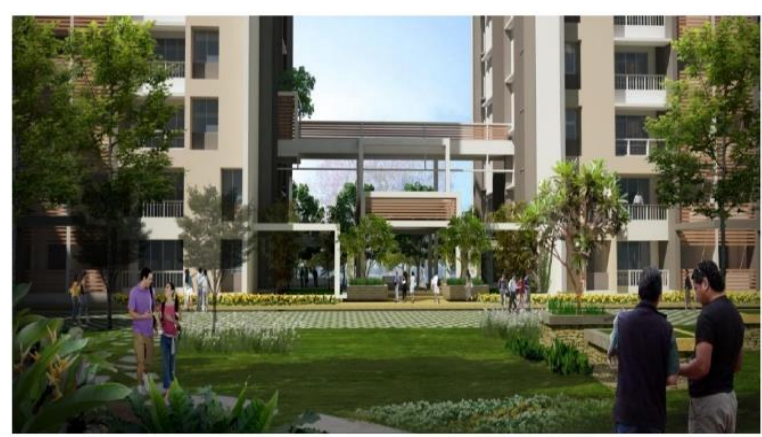

Figure 34: Internal pedestrian areas proposed for the project considered Source: Author

\section{Alternating Landscaped Terraces}

Landscaped terraces act as community break-out spaces along the connecting corridors, creating varied experiences and promote social interactions and activities along the linear spines.

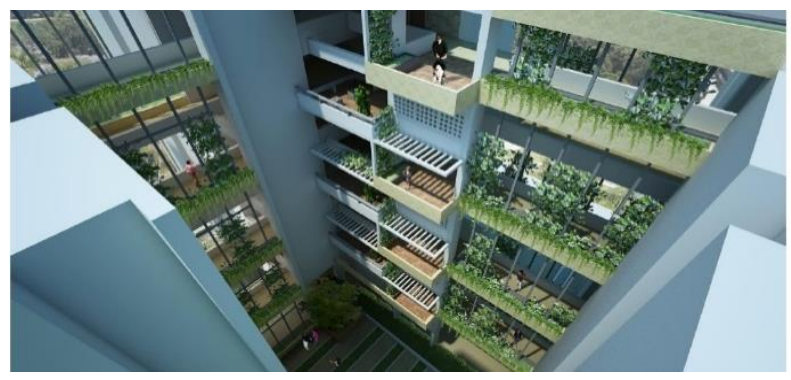

Figure 35: Alternating terraces bringing life to the internal courtyards Source: Author

\section{Interlinking Corridors}

Extending the streetscape beyond the ground plane to higher levels of building, bringing a street's character into upper levels of the building. The corridors also serve as spines linking units and blocks to one another.

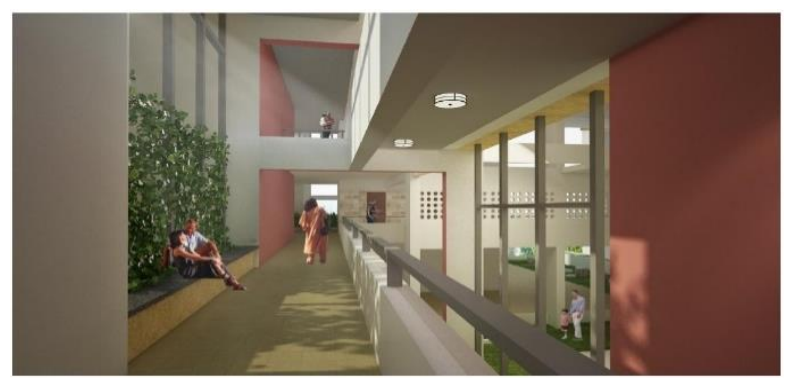

Figure 36: Interlinking Corridors with designated spaces for activities

\section{Source: Author}

\section{Personalisation of Spaces}

Corridors extend as Transitional spaces - a passage from the public realm to private. These transitional spaces 


\section{International Journal of Engineering Applied Sciences and Technology, 2020 \\ Vol. 5, Issue 1, ISSN No. 2455-2143, Pages 239-251 \\ Published Online May 2020 in IJEAST (http://www.ijeast.com)}

allow for personalisation bringing quality and identity to individual spaces.

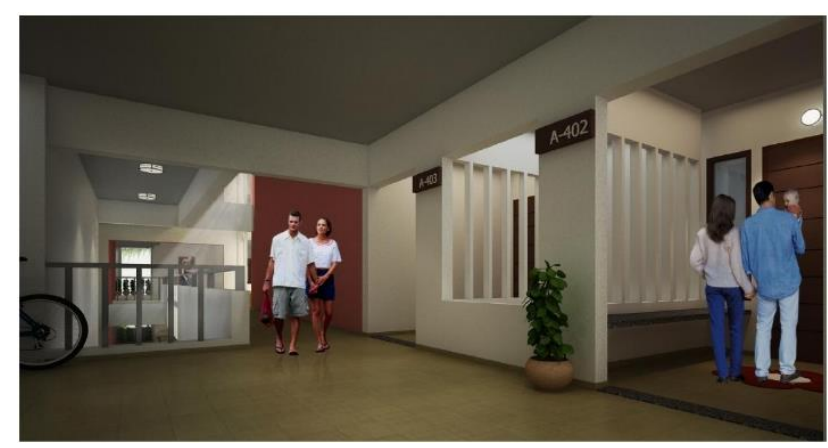

Figure 37: Transition space from public corridors to private entrance to individual houses Source: Author

\section{Initiatives: ACCESSIBILITY}

The project is envisaged to provide a barrier free environment to ensure inclusive social environment by providing comfortable and harmonious living conditions to elderly and differently-abled people.

\section{Site Circulation:}

Site circulation is developed as a barrier -free zone with terrains of the site achieved in road slopes greater than 1:20, facilitating vehicular and, pedestrian circulation along with ease of movement for differently-abled.

\section{Block Level Access:}

All blocks are provided with access ramps and lift sizes are determined so as to allow easy access to all.

\section{Public Buildings:}

All public buildings provide barrier-free access at all levels of the building, along with amenities for differently-abled.

\section{CONCLUSION}

The key to the core idea of SMART in this paper is about having a holistic approach considering and physically manifesting intangible factors along with the measurable factors. This project has key takeaways:

- Sustainable Site: $16.5 \%$ Green cover per capita.

- Water Management: $62.8 \%$ Reduction from Baseline

- Social Wellbeing: Equity and high social connect measured by Quality of life Index

- Waste Management: Net zero waste discharge and managed within the site

- Mobility: Access to all achieved, traffic free zone and first principles of pedshed at $400 \mathrm{~m}$ accomplished.

- Energy Management: Passive Right mandate followed and simulated from unit level to master plan level. Aspects of mutual shading and air funnelling achieved through simulation.

This reinforces key aspects

- Consider urban life before urban place; consider urban place before technology.

- Demonstrate sustainability, scalability and resilience over an extended timeframe.

- Demonstrate flexibility over an extended timeframe.

- New developments should demonstrate that their design takes into account the best and emerging practises, patterns forming smarter communities, smarter cities, smart urbanism, and effective place making.

The smart-cities rubric has become fashionable among global urban planners who want to use digital technology and big data to create surveillance-heavy intelligent systems that control how people live, consume energy, go to work, and stay healthy and safe. This project though exemplifies the idea of the fractal, encompassing the larger idea of SMART, which attempts to create a sustainable habitat that is holistic in performance by responding to, and balancing issues of environment, social lifestyles and economics, which can be multiplied and contribute to the larger idea of SMART and SUSTAINABLE.

\section{REFERENCES}

[1] M. Bertalmio, G. Sapiro, V. Caselles, and C. Ballester, "Image inpainting", in Proc. SIGGRAPH, pp. 417-424, 2000.

[2] A. Criminisi, P. Perez, and K. Toyama, "Region filling and object removal by exemplar-based image inpainting.", IEEE Transactions on Image Processing, vol. 13, no.9, pp. 1200-1212, 2004.

[3] Marcelo Bertalmio, Luminita Vese, Guillermo Sapiro, Stanley Osher, "Simultaneous Structure and Texture Image Inpainting", IEEE Transactions On Image Processing, vol. 12, No. 8, 2003.

[4] Yassin M. Y. Hasan and Lina J. Karam, "Morphological Text Extraction from Images", IEEE Transactions On Image Processing, vol. 9, No. 11, 2000

[5] Eftychios A. Pnevmatikakis, Petros Maragos "An Inpainting System For Automatic Image Structure-Texture Restoration With Text Removal", IEEE trans. 978-1-4244-1764, 2008

[6] S.Bhuvaneswari, T.S.Subashini, "Automatic Detection and Inpainting of Text Images", International Journal of Computer Applications (0975 - 8887) Volume 61- No.7, 2013

[7] Aria Pezeshk and Richard L. Tutwiler, "Automatic Feature Extraction and Text Recognition from Scanned Topographic Maps", IEEE Transactions 
on geosciences and remote sensing, VOL. 49, NO. 12,2011

[8] Xiaoqing Liu and Jagath Samarabandu, "Multiscale Edge-Based Text Extraction From Complex Images", IEEE Trans., 1424403677, 2006

[9] Nobuo Ezaki, Marius Bulacu Lambert , Schomaker, "Text Detection from Natural Scene Images: Towards a System for Visually Impaired Persons", Proc. of 17 th Int. Conf. on Pattern Recognition (ICPR), IEEE Computer Society, pp. 683-686, vol. II, 2004

[10] Mr. Rajesh H. Davda1, Mr. Noor Mohammed, " Text Detection, Removal and Region Filling Using Image Inpainting", International Journal of Futuristic Science Engineering and Technology, vol. 1 Issue 2, ISSN 2320 - 4486, 2013

[11] Uday Modha, Preeti Dave, “ Image InpaintingAutomatic Detection and Removal of Text From Images", International Journal of Engineering Research and Applications (IJERA), ISSN: 22489622 Vol. 2, Issue 2, 2012

[12] Muthukumar S, Dr.Krishnan .N, Pasupathi.P, Deepa. S, "Analysis of Image Inpainting Techniques with Exemplar, Poisson, Successive Elimination and 8 Pixel Neighborhood Methods", International Journal of Computer Applications (0975 - 8887), Volume 9, No.11, 2010

(Martin, Leon, \& Ortiiz, 2014)

(Salama, 2007) 